\title{
ЯЗЫКОЗНАНИЕ
}

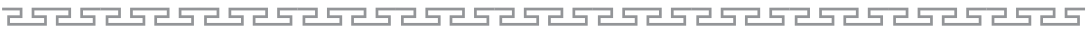

УДК 811.512 .3

DOI 10.22162/2500-1523-2019-1-146-160

\section{Характеристика звуков речи с точки зрения традиционной грамматики монгольского языка}

Characterizing Speech Sounds: a Perspective from Traditional Mongolian Grammar

\section{P. Сарангэрэл (Sarangerel Ravjir) ${ }^{I}$}

${ }^{1}$ Монгольский государственный университет образования (район Сухэ-Батор, VIII микрорайон, Бага тойру-14, г. Улан-Батор 210648, Монголия) кандидат филологических наук, преподаватель ORCID: 0000-0002-6345-9447. E-mail: sravjir@gmail.com

School for the Humanities and Social Sciences, Mongolian State University of Education (Ikh Surguuliin gudamj-1, Bagatoiruu, Sukhbaatar District, Ulaanbaatar 210648, Mongolia)

$\mathrm{Ph}$. D in Philology (Cand. of Philological Sc.), Department of Mongolian Linguistics, Lecturer

ORCID: 0000-0002-6345-9447. E-mail: sravjir@gmail.com

Аннотация. В данной статье мы попытались сравнить место и способ образования основных вариантов фонем монгольского языка с толкованием звуков речи, данным в традиционной грамматике «Огторгуйн маани», которое основано на теории пяти первоэлементов.

Ключевые слова: теория пяти первоэлементов, фонетические варианты, место и способ образования фонем, основной вариант

Для цитирования: Сарангэрэл Р. Характеристика звуков речи с точки зрения традиционной грамматики монгольского языка. Монголоведение. 2019;(1):146160. DOI 10.22162/2500-1523-2019-1-146-160.

Abstract. The paper analyzes the explanation of language sounds in The Lotus Sutra, a traditional grammatical writing of the Mongolian language, viewed from the perspectives of the theory of the Five Elements ('Five Wind Branches') - and compares the former with the sound producing ways and positions in modern Mongolian. As is shown in The Lotus Sutra, the vowel sounds used to be classified into 'masculine' $<\mathrm{a}, \mathrm{o}, \mathrm{u}>$; 'feminine' $<\mathrm{e}, \ddot{\mathrm{o}}, \ddot{\mathrm{u}}>$; and 'neutral' $<\mathrm{i}>$, however, a strong masculine sound $<\mathrm{i}>$ lost its fundamental phonetic role and turned into a neutral one. Analyzing the 
ways and positions of sound production properly prescribed in the ancient grammar, it can be concluded that there were several ways and positions to produce consonant sounds, for instance, the labial sounds - ones resulting from lip-to-teeth contact; labiodental sounds - ones resulting from lip-to-teeth contact; dental sounds - front ones articulated with the tongue touching the front teeth; and finally, alveolar sounds - ones made with the tongue touching the alveoles. The comparative study basically concludes as follows: observing some special features of the sounds $<\mathrm{a}, \mathrm{y}, \mathrm{q}, \mathrm{g}, \mathrm{g}>$ in Indian and Sanskrit languages it has properly classified the ways of sound production as those typical for 'wind element'. For example, the vowel $<\mathrm{e}>$ in Modern Mongolian has been clustered with velar (guttural) vowels, such as $<\mathrm{a}, \mathrm{y}, \mathrm{q}, \mathrm{g}, \mathrm{g}>$. This classification, in turn, is based on the natural evolution and production of the sound $\langle\mathrm{e}\rangle$. According to Sh. Luvsanvandan and U. Mandakh, the sound $<\mathrm{e}>$ could have been pronounced as a mediolingual and post-mediolingual sound. Also, the scholar Phagpa Lama clarified how the sound was pronounced in his Square Script: as Nicholas N. Poppe defined clearly, there had existed two different types of the sound $<\mathrm{e}>-$ long (open) and short (narrow) ones.

Keywords: theory of the Five Primary Elements, phonetic variants, place and method of sound production, main variant

For citation: Sarangerel Ravjir. Characterizing Speech Sounds: a Perspective from Traditional Mongolian Grammar. Mongolian Studies. 2019;(1):146-160. DOI 10.22162/2500-1523-2019-1-146-160.

\section{Введение}

Изучение языковой системы и разработка вопросов грамматики монгольского языка осуществлялись на протяжении нескольких столетий. Ярким примером стремления монголов усовершенствовать родной язык и создать грамматику служит трактат «Зүрхний тольт» (в литературе обычно дается перевод 'Сердечная сущность' или 'Сердечный покров’ [Орловская 2010: 10], 'Изъяснение сердечного покрова’ [Герасимович 2006: 87]), не дошедший до нас в оригинале. Его автор - Сажа бандида Гунгаажалцан (тиб. Сакья пандита Кунга Гьялцен), 1182-1251, известный тибетский ученый и религиозный деятель, сыгравший значительную роль в установлении тесных связей между Монгольской империей и Тибетом.

Как отмечает М. Н. Орловская, «К этому же времени восходят и монгольские лингвистические традиции, связанные прежде всего с индийской и тибетской лингвистическими школами. Монгольские грамматисты XIII-XIV вв. не только изучали и знали санскрит и тибетский языки и написанные на них древние клас- 
сические произведения, но и сами порой излагали свои стихи и трактаты на этих языках, как, например, живший и творивший в конце XIII - начале XIV в. крупнейший монгольский поэт, переводчик и ученый-филолог Чойджи-Одсэр» [Орловская 2010: 10].

Известны три сочинения «Зүрхний тольт», авторами которых являлись Сажа бандид (Сакья-пандита) Гунгаажалцан, Чойжи-Одсэр и Гунга-Одсэр, но «до нас дошли лишь сведения о том, когда и кем они были созданы, но ни одно из них до сих пор не найдено» [Герасимович 2006: 87].

Как отмечают ученые, большинство ранних монгольских грамматик не сохранилось. Исключение составляет сочинение Рав жам бы Данзандагвы (1723-1725), которое написано с опорой на труды его предшественников: Сажа бандида Гунгаажалцана, Пагба-ламы, Чойжи-Одсэра и Гунга-Одсэра и представляет собой широкое толкование сочинения Чойжи-Одсэра [Орловская 2010:13].

Сочинение Данзандагвы известно под названием «Огторгуйн маани» или, согласно содержанию, «Зүрхний тольтын тайлбар» ('Комментарии к Зүрхний тольт'). Так, в азбуке восточномонгольского князя Тогтохтура (1797-1868) говорится о сочинении Рабжамбы Данзандагвы как о трактате «лучшего из мудрецов, монлам-ламы-рабджамбы Дандзиндагвы ${ }^{1}$ „Небесные Мани, очищающие темноту заблуждений“», созданном «по повелению джунвана Лувсандаша и других» и являющемся толкованием сочинения «Зүрхни тольт» Чойджи-Одсэра [Отгоонбаатар, Цендина 2014: 37]. Далее мы называем сочинение Рабжамбы Данзандагвы «Огторгуйн маани».

Из кратких заметок, имеющихся в сочинении «Огторгуйн маани», автором которого является Рабжамба Данзандагва [Danzandagba 2015], ясно, что Сажа бандида Гунгаажалцан, озвучив 14 букв гласными звуками (a,e,i) и добавив еще (wa, we), в своем трактате определил 44 буквы. Но лабиализованные 4 звука $(\mathrm{o}, \mathrm{u}, \mathrm{ò}, \ddot{\mathrm{u}})$ и озвученные этими гласными звуками другие 52 буквы не были обозначены самостоятельными буквами: «Создавая свое

\footnotetext{
${ }^{1}$ Р. Отгоонбаатар и А. Д. Цендина в этом месте дают примечание: «Известный монгольский грамматик XVIII в.» [Отгоонбаатар, Цендина 2014: 37].
} 
сочинение $<\ldots>$ Гунгаажалцан, приспосабливая уйгурские знаки (вместе с тремя гласными их насчитывалось 17) к монгольскому языку для передачи на письме монгольской речи и разрабатывая орфографию, положил в основу алфавита индо-тибетскую слоговую систему. Хотя уйгуро-монгольское письмо по своему характеру не слоговое, а звуковое, тем не менее Гунгаажалцан и все последующие грамматисты, вплоть до начала XX в., объясняли его как слоговое по принципу индийской и тибетской слоговых систем, которые они хорошо знали» [Орловская 2010: 11-12].

В «Зүрхний тольт» Сажа бандида Гунгаажалцан не только классифицирует звуки монгольского языка на согласные и гласные, но и подразделяет гласные звуки на мужские $(\mathrm{a}, \mathrm{o}, \mathrm{u})$, женские (e, о, u) и средний (i).

Д. Тумуртого в своей работе «Вопросы теории и истории монгольской лингвистики» [Төмөртогоо 2002: 407-445] отметил, что сочинение «Зүрхний тольт» впоследствии обновлялось новыми положениями, которые выдвигали ученые ${ }^{1}$, и явилось наследием лингвистической традиции монголов, к началу ХХ в. получившим окончательную форму.

В упомянутых трудах («Зүрхний тольт», «Огторгуйн маани») звуки монгольского языка классифицированы на основе теории пяти первоэлементов. Многие исследователи отмечали, что тре-

${ }^{2}$ Оригинальные версии грамматических сочинений, посвященных монгольскому языку, — «Зүрхни тольт» (jirüken ü tolta) Сажа бандида Гунгаажалцана (XIII в.), «Зүрхни тольтын тайлбар» (jirüken-ü tolta-yin tayilburi) Чойжи Одсэра (XIV в.) не сохранились, но на их основе написаны грамматические сочинения — такие, как труды Данзандагвы «Огторгуйн маани» (Ortoryui-yin mani), Билгиндалай Шаравжамца «Монгол үсгийн толтоос өчүүхэн заавар» (Mongyol üsüg-ün tolta-ača öcüken jiłabari bolai), Дагвашарава «Монгол үсгийн утгыг чухал заасан

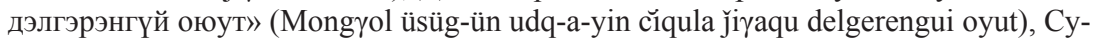
мадирадны (Лувсанринчена) «Монгол үсгийн ялгалыг үзүүлэгч тодорхой толь»

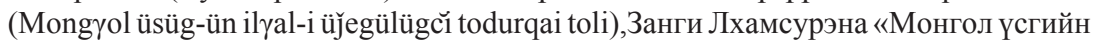
ёсыг тодорхойлон гаргасан алтан толь» (Mongyol üsüg-ün yosun-i todurqayilan yaryaysan altun toli), Онход Жамьяна «Монгол үсгийн ёсыг өчүүхэн төдий тов-

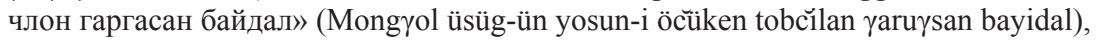
Шагжи «Монгол үсгийн тэргүүн, дунд, эцэст эгшигтэй ба дэвсгэрлэн орох ёсыг тодотгон илтгэсэн эрдэнийн сангийн түлхүүр» (Mongyol üsüg-ün terigün, dumda, ecüs-tü egesigtei ba debiskerlen oruqu yosun-i todudqan iltegügsen sang-un tülkegür) и другие [Төмөртогоо 2002: 407-445]. 
тья глава «Огторгуйн маани» представляет собой трактат о фонетике монгольского языка. Данзандагва, опираясь на принципы теории пяти первоэлементов, описал яркую картину звуков речи [Danzandagba 2015].

Нами осуществляется попытка сравнить место и способ образования основных вариантов фонем современного монгольского языка с соответствующими положениями, выдвинутыми Данзандагвой.

\section{Основная часть}

Термин «махбод» (от санскритского словосочетания «Рanca mahabhuta», берущего истоки в Древней Индии) означает 'тело, вещество, предмет, элемент, материя'. Согласно философским воззрениям древних греков, индусов и китайцев, мир и все различные явления в нем рассматривались как результат взаимодействия первоэлементов.

В Древней Греции первоосновой считали огонь, воду, землю, в Древней Индии - пространство, воздух, огонь, воду, землю, а в Древнем Китае - металл, дерево, воду, огонь, землю [Пагба 1959: 17-19].

Рассмотрим трактовки ученых-исследователей, касающиеся концепции пяти первоэлементов. Так, Г. Лхагвасурэн отмечает: «Формирование и структура любых существенных предметов объясняются взаимодействием элементов: земли, воды, дерева, огня и воздуха. Согласно буддийской философии, эти элементы влияют друг на друга и с положительной, и с отрицательной сторон ${ }^{1}$ ” [цит. по: Пагба 1959: 17-19].

С. Мёмё считает, что «согласные и гласные звуки классифицированы в соответствии с концепцией пяти элементов. Махбод (махаавхуута) - слово санскритское, означающее „тело, вещество, предмет, элемент, материя“. В древности в Греции, Индии, Китае существовало философское направление, согласно которому мир и все происходящие в нем явления считались результатом взаимодействия основных элементов...» [Мөөмөө 1979: 17-19].

\footnotetext{
${ }^{3}$ Цитаты в статье приведены в переводе 3. Баярчимэг.
} 
По мнению Д. Ганболда, «махбод - индийское слово, означающее большое вещество. Монгольское слово бодит 'вещественный' в корневой основе исходит именно из этого слова. Атом, или иными словами мельчайшая пылинка, сохраняет в себе корневые свойства земли, воды, огня, воздуха. По философскому толкованию, мельчайшая пылинка имеет массу (землю), влагу (воду), тепло (огонь), легкость (воздух) и состоит из бесчисленного множества. Космос представляет собой вакуумную среду, которая в любых условиях сохраняет пространственность» [Ганболд 2006: 111; см. также: Чулуунбат 1987: 53]

В трактате «Огторгуйн маани» Рабжамба Данзандагва классифицировал звуки согласно древнеиндийской и древнекитайской концепциям о пяти элементах [Danzandagba 2015] .

Л. Чулуунбат пишет о философской традиции Древней Индии: «Из всех ощутимых свойств, характерных для любых предметов действительности, мудрые мыслители Древней Индии выбра ли стойкость, влажность, тепло, легкость первоисточника мироздания. А выражением этих физических свойств являются земля, вода, огонь, воздух» [Чулуунбат 1987: 53]. Сравнивая это положение с современной теорией атома, ученый отмечает, что «суть первоисточников мироздания заключается в том, что элементы, являющиеся различным проявлением первичной материи, способны к взаимопревращениям: стойкость порождает твердость, влажность - плавкость, тепло - огненность, легкость - воздухообразность. Если это рассмотреть в полном соответствии с особенностью свойств частиц внутри атома, то протону и нейтрону, как компонентам ядра, присущ элемент „земля“; мезону, имеющему свойство пара, - элемент „вода“, электрону, который вращается вокруг ядра, - элемент „воздух“, а ядру, имеющему силу притяжения, - элемент „огонь“. А пятый элемент, пространство, и есть бытие» [Чулуунбат 1987: 54].

Языковеды, к примеру, ученые Ж. Санжаа и Ж. Надмид, так оценивают трактовку Данзандагвы, который классифицировал звуки речи, придерживаясь философской концепции Древней Ин дии: «...несмычные звуки обозначены буквами, которым присущ элемент „пространство“; звуки, производимые легким движе- 
нием языка, обозначены буквами элемента „воздух“; звуки, производимые движением языка вверх к нёбу, обозначены буквами элемента „огонь“; звуки, производимые при снижении языка и при смыкании губ, обозначены буквами элемента „вода“; звуки, производимые при смыкании языка и зубов, обозначены буквами элемента „земля“. Такое определение места произношения звуков, данное в традиционной грамматике, полностью совпадает с современной теорией классификации звуков речи» [Санжаа, Надмид 2008: 58]. Заслуга Данзандагвы и Чойжи-Одсэра, труд которого комментировал Данзандагва, заключается в том, что они смогли объяснить основу современной фонетики с точки зрения концепции пяти первоэлементов.

Согласно теории космогенеза китайской философии ${ }^{1}$, «мир основывается на взаимопорождении и взаимопреодолении пяти первоэлементов (начал, стихий): земли, металла (неба), воды, огня и дерева. Природа воды - быть мокрой и течь вниз. Природа огня - гореть и подниматься вверх. Природа дерева - поддаваться сгибанию и выпрямлению. Природа металла - подчиняться внешнему воздействию и изменяться. Природа земли проявляется в том, что она принимает посев, дает урожай и присутствует во всем» [ДарьхүҮ, Эрдэнэбаяр 2014: 11].

Ученые Ж. Санжаа и Ж. Надмид отмечают, что «в медицине считалось, что печени характерен элемент „дерево“, сердцу „огонь“, селезенке - ,земля“, легким — „металл“, почкам — „вода“ $<\ldots>$ И звук, согласно философской концепции китайцев, порождается струей воздуха, выходящей из сердца, селезенки, легких и почек, т. е. внутренняя чувственность и звуки трактуются в тесной связи с энергией произношения», «данное толкование интересно тем, что звуки характеризуются участием речевых органов в органической связи с деятельностью внутренних органов человека» [Санжаа, Надмид 2008: 58], «при взаимодействии пяти элементов происходят два процесса: круг порождения (или питания), т. е. огонь порождает землю, земля - металл, металл - воду, вода дерево, дерево - огонь, и круг замыкается; и круг разрушения,

${ }^{1}$ Понятие «у-син» ‘пять элементов', относящееся к основным категориям китайской философии, означает «пятичленная структура, определяющая основные параметры мироздания» [ДарьхүҮ, Эрдэнэбаяр 2014: 10-12]. 
т. е. огонь разрушает металл, металл - дерево, дерево - землю, земля - воду, вода - огонь, и опять всё замыкается. Получается, что у каждого элемента есть 2 близких ему элемента: один, который питает его, и второй, которого питает он. Есть также один „враждебный” элемент — который его разрушает. И есть один зависимый элемент, который разрушается им самим» [Пагба 1959: 17-19; цит. по: Санжаа 2011: 167].

Согласно этой концепции, «мать огня - дерево, земля — мать дерева, огонь - мать земли, а вода — враг огня, земля - враг воды, дерево - враг земли, металл - враг дерева, огонь - враг металла, т. е. каждый элемент представляет собой одно из состояний единой первоматерии - определенное сочетание основных качеств - тепла, холода, влажности и сухости: Тепло + сухость $=$ Огонь, Тепло + влажность $=$ Воздух, Холод + влажность $=$ Вода, Холод + сухость $=$ Земля» [Пагба 1959: 128].

Таблица 1. Сравнение характеристик звуков по участию органов речи, основанных на теории пяти первоэлементов

\begin{tabular}{|c|c|c|}
\hline $\begin{array}{c}\text { Пять элементов (согласно } \\
\text { древнеиндийской } \\
\text { концепции) }\end{array}$ & Буква & $\begin{array}{c}\text { Пять элементов } \\
\text { (согласно древнекитай- } \\
\text { ской концепции) }\end{array}$ \\
\hline $\begin{array}{l}\text { Пространство (порождение } \\
\text { звука из трахеи) }\end{array}$ & $\begin{array}{l}\text { Э, А, НГ, ГА, ХА } \\
\text { и родственные }\end{array}$ & $\begin{array}{l}\text { Дерево (еле слышимый } \\
\text { звук) }\end{array}$ \\
\hline $\begin{array}{l}\text { Воздух (звук, } \\
\text { произносящийся при } \\
\text { помощи кончика языка, } \\
\text { зубов и нёба) }\end{array}$ & $\begin{array}{l}\text { И, ЗА, ША и } \\
\text { родственные }\end{array}$ & $\begin{array}{l}\text { Огонь (щелевой звук, } \\
\text { произносящийся сквозь } \\
\text { верхние и нижние зубы) }\end{array}$ \\
\hline $\begin{array}{l}\text { Огонь (звук, } \\
\text { произносящийся при } \\
\text { помощи нёба) }\end{array}$ & $\begin{array}{l}\text { РА, ЯА, ЦА } \\
\text { родственные }\end{array}$ & $\begin{array}{l}\text { Металл (ротовая полость } \\
\text { открыта, язык продвинут: } \\
\text { звук, подобный пару, } \\
\text { выходящему из носа) }\end{array}$ \\
\hline Вода (губно-губной звук) & $\begin{array}{l}\text { МА, БА, ПА и } \\
\text { родственные, ВА, } \\
\text { ВЭ }\end{array}$ & $\begin{array}{l}\text { Вода (звук, подобный шуму } \\
\text { при смыкании губ) }\end{array}$ \\
\hline $\begin{array}{l}\text { Земля (звук, произносящий- } \\
\text { ся при участии кончика язы- } \\
\text { ка и зубов) }\end{array}$ & $\begin{array}{l}\text { ДА, ТА, НА, } \\
\text { ЛА, СА и } \\
\text { родственные }\end{array}$ & $\begin{array}{l}\text { Земля (звук, подобный } \\
\text { втягиванию пара в нос) }\end{array}$ \\
\hline
\end{tabular}


В трудах монгольских языковедов, в том числе Ж. Санжаа, подчеркивается, что «в традиционной грамматике, основанной на концепции пяти первоэлементов, дана нам яркая картина речепроизводства: звуки речи, производимые струей воздуха, в зависимости от признаков и действий присущего им определенного первоэлемента, со звуком-союзником соединяются сразу, а с враждебным звуком путем адаптации образуют слово или морфему, которые являются языковыми единицами, имеющими конкретное значение. Попытка сформулировать место и соединение звуков с точки зрения структурологии является главной заслугой древних языковедов-монголов» [Санжаа 2011: 167]

Д. Тумуртого отмечает, что «подразделение звуков монгольского языка по концепции пяти первоэлементов служит не только признанием вещественной стороны звуков речи, но и лингво-физиологической классификацией, отражающей место образования и способ произношения каждого звука» [Төмөртогоо 2002: 421 ].

Из всего вышесказанного следует, что различие в образовании звуков, согласно концепции пяти первоэлементов, полностью соответствует ассимиляции гласных в монгольских языках. Гармония, при которой ударный гласный в первом слоге монгольского языка определяет, какой гласный должен быть в следующем слоге, называется ассимиляцией гласных. Например: по принципу старомонгольского письма, если слово начинается с «о», то в следующих за ним слогах пишется «у»; если начинается с «а»- в следующих за ним слогах «о, у», и если в начале слова «ө», то в следующих за ним слогах — «ү». Так же в кириллическом варианте монгольской письменности, если в первом слоге «а», «у», то в следующих за ним слогах — краткий «а» (например, уран, намар). Если в первом слоге встречается гласная «ө» — в следующих слогах будет краткий «ө» (өрөг, өнөр). Если в первом слоге «э», «ү», «и», то следует в другом слоге краткий «э» (хэрэг, илбэ, Үзэм). Так же, если в первом слоге «о», то следует краткий «о» (например, орон, бороо). А в сложном слове, состоящем из двух основ, могут сочетаться «мужские» и «женские» гласные (санахгүй, учиргүй); поскольку -жээ, -чээ указывают на время действия, то, не имея 
других вариантов, пишутся они в словах и мужского и женского родов (например, гарчээ, иржээ). Для иноязычных слов правило ассимиляции гласных монгольского языка не действует.

В таблице 2 дано сравнение особенностей произношения звуков согласно концепции пяти первоэлементов (по трактату «Огторгуйн маани») с местом и способом образования основных вариантов фонем современного монгольского языка.

Таблица 2. Сравнение особенностей произношения звуков согласно концеепции пяти первоэлементов

\begin{tabular}{|c|c|c|c|c|}
\hline № & Звуки & $\begin{array}{c}\text { «Огторгуйн } \\
\text { маани» }\end{array}$ & $\begin{array}{c}\text { Место } \\
\text { образования }\end{array}$ & $\begin{array}{c}\text { Способ } \\
\text { образования }\end{array}$ \\
\hline 1 & $a$ & трахея & $\begin{array}{l}\text { задняя часть } \\
\text { языка }\end{array}$ & $\begin{array}{l}\text { ротовая полость } \\
\text { открыта: подъём } \\
\text { языка нижний }\end{array}$ \\
\hline 2 & $e$ & трахея & $\begin{array}{l}\text { передняя часть } \\
\text { языка }\end{array}$ & $\begin{array}{l}\text { подъём языка } \\
\text { средний }\end{array}$ \\
\hline 3 & $i$ & $\begin{array}{l}\text { кончик языка, } \\
\text { зубы, нёбо }\end{array}$ & $\begin{array}{l}\text { передняя часть } \\
\text { языка }\end{array}$ & $\begin{array}{l}\text { сужение ротовой } \\
\text { полости }\end{array}$ \\
\hline 4 & $o$ & лабиализация & $\begin{array}{l}\text { задняя часть } \\
\text { языка, губы }\end{array}$ & $\begin{array}{l}\text { округление губ, } \\
\text { подъём языка } \\
\text { средний }\end{array}$ \\
\hline 5 & $u$ & лабиализация & $\begin{array}{l}\text { задняя часть } \\
\text { языка, губы }\end{array}$ & $\begin{array}{l}\text { вытягивание губ, } \\
\text { сужение ротовой } \\
\text { полости }\end{array}$ \\
\hline 6 & $o 2$ & лабиализация & $\begin{array}{l}\text { задняя часть } \\
\text { языка, губы }\end{array}$ & $\begin{array}{l}\text { округление губ, } \\
\text { подъём языка } \\
\text { средний }\end{array}$ \\
\hline 7 & $u 2$ & лабиализация & $\begin{array}{l}\text { задняя часть } \\
\text { языка, губы }\end{array}$ & $\begin{array}{l}\text { вытягивание губ, } \\
\text { сужение ротовой } \\
\text { полости }\end{array}$ \\
\hline 8 & $n g$ & трахея & $\begin{array}{l}\text { задняя часть } \\
\text { языка }\end{array}$ & смыкание \\
\hline 9 & $\gamma$ & трахея & $\begin{array}{l}\text { задняя часть } \\
\text { языка }\end{array}$ & смыкание \\
\hline
\end{tabular}


МонголоведЕниЕ (Монгол сУдЛАЛ). 2019. ВыП. 1

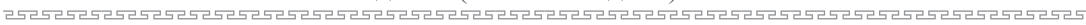

\begin{tabular}{|c|c|c|c|c|}
\hline 10 & $q$ & трахея & $\begin{array}{l}\text { задняя часть } \\
\text { языка }\end{array}$ & фрикация \\
\hline 11 & $y$ & $\begin{array}{l}\text { кончик языка, } \\
\text { зубы, нёбо }\end{array}$ & $\begin{array}{l}\text { передняя часть } \\
\text { языка }\end{array}$ & $\begin{array}{l}\text { смыкание и } \\
\text { фрикация }\end{array}$ \\
\hline 12 & $\breve{s}$ & $\begin{array}{l}\text { кончик языка, } \\
\text { зубы, нёбо }\end{array}$ & $\begin{array}{l}\text { передняя часть } \\
\text { языка }\end{array}$ & фрикация \\
\hline 13 & $\check{J}$ & нёбо, зубы & $\begin{array}{l}\text { передняя часть } \\
\text { языка }\end{array}$ & смыкание \\
\hline 14 & $r$ & нёбо, зубы & $\begin{array}{l}\text { передняя часть } \\
\text { языка }\end{array}$ & вибра-фрикация \\
\hline 15 & $c^{\breve{ }}$ & нёбо & $\begin{array}{l}\text { передняя часть } \\
\text { языка }\end{array}$ & $\begin{array}{l}\text { смыкание и } \\
\text { фрикация }\end{array}$ \\
\hline 16 & $m$ & губно-губной & губы & смыкание \\
\hline 17 & $b$ & губно-губной & губы & смыкание \\
\hline 18 & $p$ & губно-губной & губы & смыкание \\
\hline 19 & $w$ & губно-зубной & губы & фрикация \\
\hline 20 & $d$ & $\begin{array}{l}\text { кончик языка и } \\
\text { зубы }\end{array}$ & $\begin{array}{l}\text { передняя часть } \\
\text { языка }\end{array}$ & смыкание \\
\hline 21 & $t$ & $\begin{array}{l}\text { кончик языка и } \\
\text { зубы }\end{array}$ & $\begin{array}{l}\text { передняя часть } \\
\text { языка }\end{array}$ & смыкание \\
\hline 22 & $n$ & $\begin{array}{l}\text { кончик языка и } \\
\text { зубы }\end{array}$ & $\begin{array}{l}\text { передняя часть } \\
\text { языка }\end{array}$ & смыкание \\
\hline 23 & $l$ & $\begin{array}{l}\text { кончик языка и } \\
\text { зубы }\end{array}$ & $\begin{array}{l}\text { передняя часть } \\
\text { языка }\end{array}$ & $\begin{array}{l}\text { билатеральная } \\
\text { фрикация }\end{array}$ \\
\hline 24 & $s$ & $\begin{array}{l}\text { кончик языка и } \\
\text { зубы }\end{array}$ & $\begin{array}{l}\text { передняя часть } \\
\text { языка }\end{array}$ & фрикация \\
\hline
\end{tabular}

Сравнив трактовку об особенностях произношения звуков, основанную на концепции пяти элементов, с местом и способом образования фонем современного монгольского языка, мы пришли к нижеследующему выводу.

1. Труды С. Мёмё наглядно показывают, насколько творчески относился Данзандагва к анализу классификации звуков индийского санскрит-языка. Наблюдая особенность произношения звуков «А, Э, НГ, ГА, ХА и родственныХ», он сумел точно определить, 
что «букве, обозначающей звук, который производится без каких-либо препятствий, характерен первоэлемент воздух» [Мөмөө 1979: 15]. К тому же, гласный звук е современного монгольского языка отнесли к ряду таких звуков, как $a, \tilde{\eta}, q, k g \mathrm{~g}$, относящихся к звукам задней части языка. Предполагаем, это может быть связано с происхождением и эволюцией гласного $e$, при порождении которого струя воздуха, выходящая из легких, не встречает препятствий. Ученые Ш. Лувсанвандан, О. Мандах предполагают, что когда-то звук $е$ произносился в среднем и за средним рядом языка [Санжаа 2011: 164].

Н. Н. Поппе, детально изучивший квадратное письмо, которое сочинил Пагба-лама Лодойжалцан, подчеркнул, что в квадратном письме существовали два звука $е$, один из которых довольно открытый $e$, а второй - узкий $e$ [Поппе 1941: 34].

2. Исходя из подразделения гласных звуков на мужские $(\mathrm{a}, \mathrm{o}, \mathrm{u})$, женские (e, o, u) и средний (i), данные в «Огторгуйн маани», мы предполагаем, что громкий мужской (i) потерял самостоятельную функцию фонемы.

3. По месту происхождения губные и смычные звуки образованы при смыкании губ, звуки переднего ряда языка - при смыкании кончика языка, зуб и нёба. Иными словами, смычка или фрикация речевых органов являются ярким примером того, как подробно толковались место и способ образования согласных в традиционной грамматике. Точно также были определены способы произношения вибро-фрикативного звука $r$ и билатеральнофрикативного звука $l$.

Взаимопорождение и взаимопреодоление пяти элементов заключается в следующем: дерево, порождая огонь, побеждает землю; огонь, порождая землю, побеждает металл; земля, порождая металл, побеждает воду; металл, порождая воду, побеждает дерево; вода, порождая дерево, побеждает огонь.

Мы предполагаем, что детальное изучение этого взаимопорождения в тесной связи с признаками звуков речи, поможет нам раскрыть и другие стороны таких языковых явлений, как чередование и изменение звуков. 
МонголоведЕНИЕ (Монгол СУдЛАЛ). 2019. ВЫП. 1

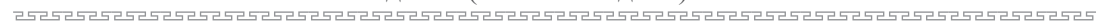

Таблица 3. Связи пяти элементов

\begin{tabular}{|l|l|l|l|l|l|}
\hline $\begin{array}{l}\text { Взаимопорождение/ } \\
\text { Взаимопреодоление }\end{array}$ & Дерево & Огонь & Земля & Металл & Вода \\
\hline Мать & Вода & Дерево & Огонь & Земля & Металл \\
\hline Сын & Огонь & Земля & Металл & Вода & Дерево \\
\hline Союзник & Земля & Металл & Вода & Дерево & Огонь \\
\hline Враг & Металл & Вода & Дерево & Огонь & Земля \\
\hline
\end{tabular}

\section{Источники}

Danzandagba 2015 - Danjandayba. Jirüken-ü toltu-yin bič́g nigen debter

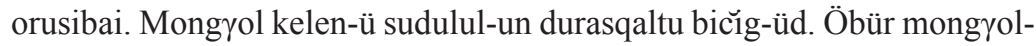
un keblel-ün bülüglel. Öbür mongyol-un soyol-un keblel-ün qoriy-a, Mongyol tulgar bičig-un cubural. 2015.

\section{Sources}

Danjandayba. Jirüken-ü toltu-yin bič̆g nigen debter orusibai [The Mirror of

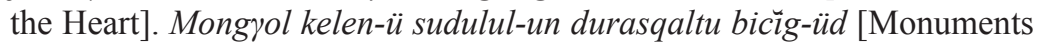
of Mongol linguistics]. Hohhot: Inner Mongolia Culture Press, 2015. Mongrol tulgar bič̀g-un cübural [Series 'Collected (Ancient) Mongolian Sources']. (In Mong.)

\section{ЛИТЕРАТУРА}

Ганболд 2006 - Ганболд Д. Монгол сан тахилгын судар үгийн урлагийн туурвил болох нь. Улаанбаатар: Соёмбо пресс, 2006. 165 х.

Герасимович 2006 - Герасимович Л. К. Монгольская литература XIII начала XX вв. Материалы к лекциям. Элиста: НПП «Джангар», 2006. $362 \mathrm{c}$.

Дарьхүу, Эрдэнэбаяр 2014 - ДарьхҮY Р., Эрдэнэбаяр Г. Философийн түүх (История философии). Улаанбаатар: Бит сервис, 2004. 142 х.

Мөөмөө 1979 - Мөөмөө С. Орчин цагийн монгол хэлний авиан зүй / Ред. С. Галсан. Улаанбаатар: Улсын хэвлэлийн газар, 1979. 198 х.

Орловская 2010 - Орловская М. Н. Очерки по грамматике языка древних монгольских текстов. М.: Вост. лит., 2010. 303 с. 
Отгонбаатар, Цендина 2014 - Отгонбаатар Р., Цендина А. Д. Образцы письменной традиции Северной Монголии: алфавиты, транскрипции, языки (конец XVI — начало XX в.). М.: Наука - Вост. лит., 2014. $240 \mathrm{c}$.

Пагба 1959 - Пагба T. «Зүрхний тольтын тайлбар»-ыг судалсан тухай тэмдэглэл / ред. Ц. Дамдинсүрэн. Улаанбаатар: Улсын хэвлэлийн газар, 1959. 64 x.

Поппе 1941 - Попnе Н. Н. Квадратная письменность. М.; Л.: Изд-во АН СССР, 1941. $166 \mathrm{c}$.

Санжаа, Надмид 2008 - Санжаа Ж., Надмид Ж. Монгол хэлний авиазүй ба авиалбарзүй / Ред. С. Мөөмөө. Улаанбаатар: Улсын хэвлэлийн газар, 2008. 296 x.

Санжаa 2011 - Санжаа Ж. Монгол хэлний их авиалбар, авиалбар, авианы тогтолцоо. Улаанбаатар: Улсын хэвлэлийн газар, 2011. 518 х.

Төмөртогоо 2002 - Төмөртогоо Д. Монгол хэл шинжлэлийн онол түүхийн асуудлууд. Улаанбаатар: Бэмби сан, 2002. 549 х.

Чулуунбат 1987 - Чулуунбат Л. Үсгийг махбодоор ялгах ёсны тухай // Хэл зохиол судлал. 19-р боть, Улаанбаатар: Улсын хэвлэлийн газар, 1987. $191 \mathrm{x}$.

\section{REFERENCES}

Ganbold D. Mongol san takhilgyn sudar ügiyn urlagiyn tuurvil bolokh n' [Preliminary notes on the oral tradition related to Mongolian incense offering sutras (texts)]. Ulaanbaatar: Soembo Press, 2006. 165 p. (In Mong.)

Gerasimovich L. K. Mongol'skaya literatura XIII - nachala XX vv. Materialy $k$ lektsiyam [Mongol literature of the $13^{\text {th }}-$ early $20^{\text {th }} \mathrm{cc}$. Lecture materials]. Elista: Dzhangar, 2006. 362 p. (In Rus.)

Darkhüü R., Erdenebayar G. Filosofiyn tüükh [History of philosophy]. Ulaanbaatar: Bit Servis, 2004, 142 p. (In Mong.)

Möömöö S. Orchin tsagiyn mongol khelniy avian züy [Phonetics of Modern Mongolian]. S. Galsan (ed.). Ulaanbaatar: State Publ. House, 1979, 198 p. (In Mong.)

Orlovskaya M. N. Ocherki po grammatike yazyka drevnikh mongol'skikh tekstov [Essays on the grammar of the language of ancient Mongolian texts]. Moscow: Vost. Lit., 2010. 303 p. (In Rus.)

Otgonbaatar R., Tsendina A. D. Obraztsy pis'mennoi traditsii Severnoi Mongolii: alfavity, transkriptsii, yazyki (konets XVI - nachalo XX v.) [Samples of the written tradition of Northern Mongolia: alphabets, transcriptions, languages (late $16^{\text {th }}-$ early $20^{\text {th }} \mathrm{cc}$.) $]$. Moscow: Nauka Vost. Lit., 2014. 240 p. (In Rus.) 
Phagpa T. «Zürkhniy tol'tyn taylbar»-yg sudalsan tukhay temdeglel [Notes to studies of The Mirror of the Heart]. Ts. Damdinsüren (ed.). Ulaanbaatar: State Publ. House, 1959, 64 p. (In Mong.)

Poppe N. N. Kvadratnaya pis'mennost' [The Square Script]. Moscow; Leningrad: USSR Acad. of Sc., 1941. 166 p. (In Rus.)

Sanzhaa Zh., Nadmid Zh. Mongol khelniy aviazüy ba avialbarzüy [Mongolian phonetics and phonology]. S. Möömöö (ed.). Ulaanbaatar: State Publ. House, 2008, 296 p. (In Mong.)

Sanzhaa Zh. Mongol khelniy ikh avialbar, avialbar, aviany togtoltsoo [The system of Mongolian phonemes and sounds]. Ulaanbaatar: State Publ. House, 2011.518 p. (In Mong.)

Tömörtogoo D. Mongol khel shinzhleliyn onol tüükhiyn asuudluud [Mongol linguistics: problems of history and theory]. Ulaanbaatar: Bembi San, 2002. 549 p. (In Mong.)

Chuluunbat L. Üsgiyg makhbodoor yalgakh esny tukhay [Separation of letters in accord with macroelements]. Khel zokhiol sudlal [Linguistics]. Vol. 19. Ulaanbaatar: State Publ. House, 1987, 191 p. (In Mong.). 